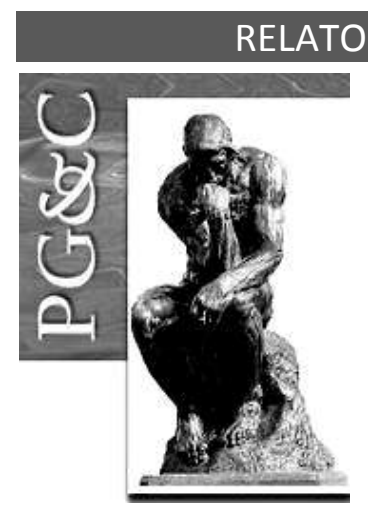

\title{
CENÁRIOS PROSPECTIVOS PARA IMPLANTAÇÃO DE COMUNIDADES DE PRÁTICA EM UNIDADES DE CONTABILIDADE EM UNIVERSIDADES PÚBLICAS
}

\author{
Suzana de Lucena Lira \\ Doutoranda em Ciência da Informação pela Universidade Federal da \\ Paraíba, Brasil. \\ E-mail: suzanalira@hotmail.com \\ Wagner Junqueira de Araújo \\ Doutor em Ciência da Informação pela Universidade de Brasília, Brasil. \\ Professor da Universidade Federal da Paraíba, Brasil. \\ E-mail: wagnerjunqueira.araujo@gmail.com \\ Emeide Nóbrega Duarte \\ Doutora em Administração pela Universidade Federal da Paraíba, Brasil. \\ Professora da Universidade Federal da Paraíba, Brasil. \\ E-mail: emeide@hotmail.com
}

\begin{abstract}
Resumo
Esta pesquisa tem como objetivo desenvolver a informação estratégica por meio da construção de cenários prospectivos para proposição de uma comunidade de prática (CoP) na área contábil de universidades públicas, como ferramenta para auxiliar na gestão do conhecimento. Apresenta diferentes perspectivas da literatura para implementação de ferramentas de gestão do conhecimento e comunidades de prática. Trata-se de um estudo de cunho descritivo, com a utilização de abordagem quali-quantitativa e uso de um método de cenário prospectivo. Como suporte metodológico para desenvolvimento dos cenários utiliza o método proposto por Godet. Com as informações identificadas e inferências propostas pelo método, foram desenvolvidos três cenários com base nos indicadores prováveis: um cenário otimista, onde a CoP se configura como uma idéia bem aceita e de importância para a área; um cenário que requer reflexão antes de qualquer implantação; e, outro cenário de visão pessimista com a sugestão de não implementação de CoP. Como resultado este trabalho oferece subsídios aos gestores interessados em implantar uma CoP em unidades contábeis, os cenários elaborados permitem ordenar etapas futuras e podem auxiliar no planejamento estratégico e na tomada de decisão.
\end{abstract}

Palavras-Chave: Gestão da informação e do conhecimento. Comunidade de prática. Cenário prospectivo. Informação estratégica.

\section{PROSPECTIVE SCENARIOS FOR INTRODUCTION OF COMMUNITIES OF PRACTICE IN ACCOUNTING UNITS IN PUBLIC UNIVERSITIES}

\begin{abstract}
This research proposed to develop strategic information through the construction of prospective scenarios to propose a community of practice $(\mathrm{COP})$ in the accounting area of public universities, as a tool to help in knowledge management. It presents different perspectives of the literature for the implementation of knowledge management tools and communities of practice. We chose a descriptive study, using a qualitative-quantitative approach and use of a prospective scenario method. The methodology proposed by Godet was used as methodological support for scenario development. With
\end{abstract}

Perspectivas em Gestão \& Conhecimento, João Pessoa, v. 7, n. 1, p. 170-190, jan./jun. 2017. DOI: http://dx.doi.org/10.21714/2236-417X2017v7n1p170

http://periodicos.ufpb.br/ojs2/index.php/pgc. ISSN: 2236-417X. Publicação sob Licença (cc) EY-Nc-ND 
the identified information and inferences proposed by the method, three scenarios were developed based on the probable indicators: an optimistic scenario, where the CoP is configured as a well-accepted and important idea; A scenario that requires reflection before any deployment; And another scenario of pessimistic vision with the suggestion of non-implementation of CoP. As a result, this work offers subsidies to managers interested in carrying out a COP in accounting units, the scenarios elaborated allow to order future steps and can aid in tactical planning and decision making.

Keywords: Information and knowledge management. Community of practice. Prospective scenario. Strategic information.

\section{INTRODUÇÃO}

A construção do conhecimento se verifica por meio de um processo complexo, que conjuga a cognição, a percepção sensorial, a experimentação e o algo a mais do indivíduo, que vai além dos sentidos e é reconhecido como intuição. Nas organizações isso é desenvolvido e aplicado pelos indivíduos que detêm um arcabouço de conhecimentos prévios, uma visão de mundo e se nutrem de novas informações, construindo novos conhecimentos.

$\mathrm{Na}$ Ciência da Informação (Cl), tanto a gestão do conhecimento (GC) como a informação estratégica (IE) são temas recorrentes em seus estudos. Como o conhecimento reside nas pessoas, a tarefa da gestão do conhecimento é de se utilizar de métodos, técnicas, instrumentos e ferramentas que ajudam as pessoas a explicitar e transmitir o conhecimento construído, de forma a compartilhá-lo no ambiente organizacional (SILVA; VALENTIM, 2008).

A gestão do conhecimento surge com uma proposta de promover a interação entre os diversos indivíduos que compõem as organizações, por meio de capacitadores, de favorecimento de ambientes propícios onde o conhecimento floresce, por meio de práticas e de ferramentas que proporcionem a criação e a transformação de novos conhecimentos, de maneira ordenada às necessidades da organização e de sua gestão. Um dos principais desafios na GC está na ordenação deste capital intelectual que é gerado em uma organização e como possibilitar que este seja partilhado eficazmente por meio de processos e redes formais e informais.

Uma das ferramentas utilizadas na GC é conhecida como comunidade de prática (CoP), por meio da qual o conhecimento pode ser compartilhado de forma ordenada. É formada por grupos de interesse em área comum, que possam, por meio presencial ou virtual, expor ideias e experiências, partilhar problemas e, juntos, encontrar soluções.

As CoP são descritas por Duarte et al. (2008, p. 82) como "grupos formados em torno da prática de sua profissão que são ligados pela necessidade de partilhar experiências e desenvolver conhecimento coletivo". Por isso, a possibilidade de se propor uma CoP junto aos contadores das universidades federais pode ser de grande valia na construção e aperfeiçoamento do conhecimento técnico profissional destas instituições.

Assim, este estudo procura responder ao seguinte questionamento: O setor contábil de uma universidade pública federal está preparado para formar uma comunidade de prática?

O objetivo proposto foi objetivo desenvolver a informação estratégica por meio da construção de cenário prospectivo para proposição de uma comunidade de prática (CoP) na área contábil de universidades públicas.

Para identificar elementos que orientem os envolvidos no processo de tomada de decisão sobre a viabilidade de implantação de uma CoP, esta pesquisa utilizou o método de cenários prospectivos de Godet. Tarapanoff $(1995$, p. 28$)$ conjuga "os fatores de prospecção que se fundam no conhecimento da organização ou sistemas informacionais no passado", para

Perspectivas em Gestão \& Conhecimento, João Pessoa, v. 7, n. 1, p. 170-190, jan./jun. 2017. 
vislumbrar possíveis cenários. Os métodos de cenários são utilizados para identificar, organizar, analisar e oferecer uma informação para orientar na tomada de decisões.

Desta forma este artigo foi estruturado em seis tópicos, o primeiro introduz o estudo proposto, os dois seguintes discorrem sobre a gestão do conhecimento, comunidades de prática, informação estratégica e cenários prospectivos. O quarto tópico apresenta os procedimentos metodológicos adotados e o quinto a análise e o desenvolvimento dos cenários. Por fim, as considerações sobre os resultados obtidos.

\section{A GESTÃO DO CONHECIMENTO E A COMUNIDADE DE PRÁTICA}

Lira (2012) demonstra aspectos positivos para as ações de gestão da informação e do conhecimento no setor contábil da Universidade Federal da Paraíba (UFPB) constatado por meio da análise de diagnóstico de GC, que teve como resultado os fluxos informais que possibilitaram identificar os aspectos de aprendizagem, compartilhamento, desprendimento e nova percepção de conhecimento, tanto por meio de sua inovação quanto da recriação.

A gestão do conhecimento para Duarte et al. (2014, p. 269) é muito mais do que "simplesmente administrar, gerir, conduzir", é também o ato ou efeito de fazer com que as pessoas compartilhem atividades, obrigações e competências que façam parte da vida das organizações às quais pertençam, ou seja, que as pessoas sintam-se inseridas no contexto, sem impor algum tipo de ordem sobre o conhecimento.

Para Barbosa (2013, p. 3) a possibilidade de "gerenciar o conhecimento pessoal" parte de como as diversas áreas do saber definem conhecimento e reconhece que na área das ciências sociais encontra-se associado à inovação, aprendizagem, capital intelectual, compartilhamento do conhecimento, conhecimento tácito, cultura organizacional, dentre outros. $\mathrm{O}$ autor complementa que no campo das ciências sociais o conceito de GC associa-se a aspectos de natureza essencialmente comportamental.

Araújo (2014, p. 64) trata da GC como uma das "subáreas da ciência da informação" e considera a informação um importante recurso para as organizações, mas não necessariamente a que existe materialmente, e sim a que ainda não existe como entidade física, materializada, a que está na mente das pessoas que fazem a organização. Faz referência a Polanyi (1968) e suas contribuições a respeito das concepções dos tipos de conhecimento tácito e explícito, que foram fundamentais para o avanço desta área.

O conhecimento explícito é a informação registrada em algum suporte e é a que interessa à gestão da informação, que por meio de seus processos de disseminação e uso da informação, proporciona o acesso e disponibilização da informação para quem dela necessita. Já o conhecimento tácito, que é o que perpassa a mente das pessoas e que ainda não foi explicitado, que pode ser percebido nas conversas informais é o de interesse da GC, o que pode contribuir por intermédio de seus processos e ferramentas, a interação e o compartilhamento do conhecimento, propiciando a evolução tanto do conhecimento individual, quanto do organizacional.

Gutierrez (2008) reconhece que o conhecimento tácito é mais difícil de ser transmitido que o conhecimento explícito. Necessita-se do contato humano para que o conhecimento tácito seja explicitado de forma espontânea entre os indivíduos que possuem determinado conhecimento e os que desejam conhecer. Assim sendo, as estratégias que podem ser usadas pelas organizações para propiciar e incrementar este conhecimento são incentivar a interação por meio de comunidades de prática, feiras de conhecimento, cursos que formem multiplicadores ou criar uma cultura organizacional que facilite os contatos informais entre seus membros.

O autor identifica que um dos passos para a GC numa organização é a implementação de sistemas cujo principal objetivo é que todos os tipos de conhecimento envolvidos na

Perspectivas em Gestão \& Conhecimento, João Pessoa, v. 7, n. 1, p. 170-190, jan./jun. 2017. 
instituição: tácito, explícito, individual, interno e externo, possam se transformar e se converter em conhecimento corporativo, de maneira que esse conhecimento, passando a ser acessado e compartilhado, redunde em aumento do conhecimento individual de seus membros e proporcione diretamente em uma melhor contribuição desses sujeitos na consecução dos objetivos da organização.

Para Duarte et al. (2014) as CoP são grupos de pessoas e/ou instituições de uma mesma área de conhecimento, que compartilham experiências para solucionar problemas, encontrar ideias, melhorar as práticas e preservar e aprimorar sua capacitação e competência. Compõem-se de redes de indivíduos que trabalham juntos, dividindo conhecimentos e compartilhando problemas comuns, histórias e frustrações. Tendem a continuar sua dinâmica por tempo indeterminado, diferentemente do que ocorre com os projetos convencionais.

Takimoto (2012) indica três componentes estruturais que caracterizam as comunidades de prática: domínio, comunidade e prática. O domínio, como elemento fundamental de uma comunidade de prática, corresponde a uma área de conhecimento, interesse ou atividade humana, nesse caso, a área contábil das universidades federais. A comunidade, como elemento central de uma CoP, é composta de indivíduos, suas interações e a construção de relacionamentos, ou seja, os contadores pertencentes aos quadros dessas instituições, que aplicam seus conhecimentos em suas atividades; e a prática, que envolve o conhecimento compartilhado pelos membros (incluindo um conjunto de estruturas, ferramentas, informações, estilos, linguagem, histórias, documentos e compreensão).

Nas comunidades de prática, como uma ferramenta de GC, a relação entre os participantes - tanto a presencial quanto a virtual - é de extrema importância, pois a colaboração, a disponibilização de procedimentos, práticas, documentos, conteúdos e conhecimentos, bem como a integração entre os colaboradores e a gestão desse ambiente são determinantes para resultados positivos do processo de gestão do conhecimento.

Álvares (2010) define a comunidade de prática como "grupos de pessoas que têm em comum uma preocupação, um conjunto de problemas ou uma paixão acerca de um tema e que desenvolvem o seu conhecimento e especialização nessa área, interagindo em uma base regular". A autora complementa que também são conhecidas por comunidades de aprendizagem.

Silva (2010) evidencia que nas comunidades de prática os membros aprendem e desaprendem constantemente, e que a cada encontro formal ou informal e/ou troca de emails, os significados são negociados e renegociados, tornando definidas as melhores práticas para a realização das atividades, o que, por meio de um consenso coletivo, gera novos conhecimentos. Duarte e Silva $(2007$, p. 98) evidenciam que a "aprendizagem organizacional surge da necessidade de contínua aprendizagem como forma de enfrentar as mudanças macro e microambientais".

Na concepção de Mengalli $(2007$, p.2) gerir e compartilhar conhecimento faz parte do conceito de Comunidades de Prática, ou seja, "partilhar a temática no contexto da estrutura social". As CoP ultrapassam os limites tradicionais de coligação ou trabalho em conjunto, assim como o espaço físico e geográfico. As relações de contribuição têm um caráter espontâneo, não hierarquizado e autogerido. Desenvolvem-se juntamente com colaboradores e gestores, e tende a uma relação de confiança, uma vontade de aprender uns com os outros e uma participação responsável. Terra (2005) especifica que a CoP reúne pessoas que, no curso normal de trabalho, não se encontrariam.

As redes virtuais de compartilhamento formam ações de gestão do conhecimento, onde o conteúdo é partilhado de forma espontânea pelos membros de uma comunidade, tornando-os pertencentes ao grupo, formando assim, a comunidade de prática, que é uma ferramenta de suma importância para o desenvolvimento de práticas de GC. 
As redes de compartilhamento, presenciais ou virtuais, com flexibilidade de interação e conexão entre os membros de diferentes formas de comunicação precisam ser estimuladas nas organizações. Contudo, quando estas devem ser implantadas ou se a organização está apta para receber uma CoP é sempre algo que deve ser planejado, para este planejamento é necessário buscar informações que subsidiem a tomada de decisão minimizando as incertezas.

\section{A INFORMAÇÃO ESTRATÉGICA E CENÁRIOS PROSPECTIVOS}

A informação é um agente dissipador de incertezas cujo objetivo é proporcionar alterações no comportamento das pessoas. A contextualização é a principal característica para a informação. Para Davenport (1998) a gestão da informação preocupa-se com o indivíduo, o que este precisa e como utiliza a informação. A informação proporciona a inovação também por meio da aprendizagem. Aliada à aprendizagem, tem-se a inteligência competitiva, que visa a antecipar mudanças no ambiente competitivo (COHEN, 2002).

A informação é considerada estratégica quando possui elementos que possam ser utilizados com foco no futuro, obtida por meio de monitoramento ambiental ou prospecções. Para Calazans (2006) a conceituação e a definição do uso da informação estratégica permitem maior conhecimento do ambiente informacional e da sua gestão, porque possibilita identificar características, funcionalidades, necessidades e valores na organização. $\mathrm{O}$ autor considera a informação organizacional com características e dimensões específicas, em que o objetivo principal da informação estratégica, é o uso de dados, informação e conhecimento para agregação de valor a produtos e/ou serviços, garantindo a sobrevivência da organização aos desafios atuais.

Em uma organização, a aliança entre os sujeitos é derivada da formação e manutenção de um grupo que almeja o mesmo objetivo, e que possui padrões, modelos, regras e comportamentos comuns, resultando na cultura organizacional, que pode ser interpretada como sendo produto das manifestações, interações e absorção desses modelos e padrões de indivíduos que interagem, e são membros de uma mesma organização. Promover a interação entre os indivíduos de forma que as culturas sejam aceitas individualmente e coletivamente, inclusive no convívio com as diferenças, não é uma tarefa fácil de ser empreendida: quando se trata de informação estratégica, é necessário que os conjuntos de padrões e semelhanças culturais sejam ajustados, de forma que passem a interpretar a gestão estratégica da informação como algo indispensável para a organização (CÂNDIDO et al., 2005).

Para Leitão (1993, p. 121) informação estratégica é aquela que caracteriza o "processo estratégico", ou seja, está ligada ao ambiente externo e ao futuro da organização. É ela que permite a construção de possíveis futuros por meio de especulações desenvolvidas para prever a evolução do ambiente externo, das oportunidades e ameaças que esses possíveis futuros possam apresentar para a organização.

Patel (2016) evidencia três contribuições fundamentais para o planejamento de cenários futuros: melhorar a atenção de gestores e tomadores de decisão para os ambientes dinâmicos em que operam; melhorar a escolha feita pelos indivíduos, uma vez que repercebem, ou seja, melhor compreendem o conhecimento; e, aprofundamento dos participantes na consciência da 'essência' porque sai de suas próprias suposições, leva ao tipo de criatividade que pode produzir opções estratégicas resilientes nas organizações. $O$ autor reconhece que prospecção não é predição, ao contrário, percebeu na prospectiva de cenários um alcance de "novas percepções que levam a insights estratégicos que estavam previamente fora do alcance da mente" para que o indivíduo pudesse ter "um aha!" - "experiência" (PATEL, 2016).

Para a previsão, o "cenário" é construído para que a organização se prepare para ele (ou se torne refém dele); no caso da construção prospectiva, os "cenários" são construídos

Perspectivas em Gestão \& Conhecimento, João Pessoa, v. 7, n. 1, p. 170-190, jan./jun. 2017. 
para que a organização saiba tomar as decisões adequadas caso um deles se deflagre (MORESI et al., 2010).

Godet (2006, p. 6) trata como gêmeos fraternos, "a prospectiva e a estratégia", mas evidencia que estas continuam entidades distintas, fazendo-se necessário distingui-las: a fase de antecipação, ou seja, o estudo das mudanças possíveis e desejáveis, e a fase de preparação, qual seja, o trabalho externo e a avaliação de possíveis escolhas estratégicas, de modo a estar preparado para esperar mudanças (pré-atividade) e provocar mudanças desejáveis (próatividade). Godet (2011, p. 9) demonstra que "a ação sem finalidade não tem sentido e a antecipação suscita a ação. É por isso que a Prospectiva e a Estratégia são, em geral, indissociáveis e, daí, a expressão prospectiva estratégica". O autor complementa:

Dado que o futuro pertence ao domínio da vontade, a Prospectiva deve ter por objetivo tornar a ação eficaz. Não se trata de construir uma teoria da ação, mas, sobretudo uma ciência da prática que, mais do que uma simples aplicação dos métodos científicos aos problemas humanos, deverá constituir uma verdadeira mudança de perspectiva; o objeto não consiste em observar o futuro a partir do presente, mas, pelo contrário, observar o presente a partir do futuro. Esta mudança de perspectiva implica fazer a escolha de um futuro entre os muitos futuros possíveis e põe em primeiro plano, mais uma vez, o problema da finalidade da ação (GODET, 2011, p. 5).

$\mathrm{Na}$ literatura é possível verificar diferentes métodos e abordagens para o desenvolvimento de cenários prospectivos. Para fins deste trabalho serão descritos de forma sucinta o modelo das cinco forças de Porter, modelo de análise de cenários proposto por Lee et al. (2015), o método delphi, além da proposta de Godet (2006).

De acordo com Carvalho et al. (2011, p. 6) "o modelo das cinco forças de Porter (1996)", representa a análise da competitividade e atratividade de um setor sob a ótica de cinco principais elementos: rivalidade entre os concorrentes; ameaça de novos competidores entrando no mercado; poder de negociação de compradores; poder de barganha de fornecedores; e ameaça de produtos ou serviços substitutos. Citando Ghemawat (2007), para quem o ambiente do setor onde a organização opera tem forte influência sobre seu desempenho econômico, parte da análise de três estruturas, segundo ele mais genéricas, que foram apresentadas como soluções para a formulação de cenários de negócios: análises individuais da oferta-demanda de mercado; estrutura de "cinco forças" proposta por Porter para análise de setores; e a "rede de valor" apresentada por Adam Brandenburger e Barry Nalebuff. Ainda segundo Ghemawat (2007), o principal objetivo de se fazer o exercício de mapeamento de cenários é o de sugerir formas por meio das quais as empresas podem se adaptar e moldar os cenários nos quais estão inseridas (CARVALHO et al., 2011).

Ao referir a Schwartz (2000), os autores relatam que o cenário é uma base para conversões estratégicas que levam à aprendizagem organizacional constante com relação a decisões-chaves e prioridades. Para tanto, deve-se escolher de três a cinco futuros mais representativos e fazer com que a organização reflita sobre os mesmos.

O objetivo da criação de cenários não é uma fotografia precisa do amanhã, mas dar subsídios para tomar decisões estratégicas mais acertadas e abrangentes. A análise de futuro é componente importante de um processo de gestão estratégica dinâmico. A discussão de cenários futuros pode aprimorar a tomada de decisão organizacional e alinhar a estratégia presente de uma organização segundo as opções vislumbradas. A possibilidade de se trabalhar com visões de futuro e de delimitar as incertezas prepara a empresa hoje para eventos futuros sem análises e trabalhos demasiadamente caros e longos (CARVALHO et al., 2011). 
O modelo de análise de cenários proposto por Lee et al. (2015) traz uma abordagem sistemática para avaliar os impactos de alterações futuras em planos organizacionais, integrando os pontos fortes de análise de sensibilidade, para lidar com a variabilidade intrínseca de sistemas, dentro da tecnologia de mapeamento de rota baseada em cenários. 0 foco da abordagem proposta é uma rede Bayesiana que pode examinar as relações de incerteza e dependência associada a um processo complexo utilizando um conjunto de variáveis aleatórias. A abordagem sugerida incorpora as questões de incerteza e de impacto. Destina-se a ser executada em três fases distintas: designar um roteiro e suas relações causais; avaliar os impactos de mudanças futuras sobre os planos organizacionais através de análise do estado atual e de sensibilidade; e, gestão de planos e atividades via desenvolvimento de mapa de avaliação de plano e de atividade.

Além deste, segundo Grisi e Brito (2003) o método delphi pode ser aplicado para prospecção e consiste em rodadas com especialistas, os quais estabelecem as variáveis e indicadores críticos para avaliar os eventos prováveis, que são submetidos a julgamentos após cada fase, ocorrendo o aperfeiçoamento das hipóteses, para se buscar o cenário mais provável.

\begin{abstract}
Há, nesse método, a despeito de possíveis variações em sua aplicação, três premissas básicas. Como se pretende reunir as idéias de especialistas, mas evitar que haja influência prévia das idéias de uns sobre os outros e também o constrangimento de eventuais mudanças futuras de opinião, busca-se garantir o anonimato dos respondentes.

A segunda premissa é a representação estatística dos resultados de cada rodada de questões. Quando as respostas da primeira rodada voltarem e forem tabuladas, o ideal é que sejam feitas representações estatísticas de modo a possibilitar, para a segunda rodada, uma melhor visualização por parte dos respondentes, de qual a sua posição perante o grupo. Adicionalmente, a representação estatística oferece a possibilidade de o organizador dos debates acompanhar o processo de criação do consenso entre os especialistas, objetivo central da técnica.

Por fim, já mencionado acima, o método delphi implica o feedback de respostas do grupo para reavaliação nas rodadas subseqüentes. Tanto as respostas fechadas quanto as abertas deverão ser tabuladas e reenviadas, anonimamente, aos respondentes, para que suas visões possam ser aprofundadas (GRISI; BRITTO, 2003, p. 9).
\end{abstract}

Portanto, o método delphi é um processo coletivo, que envolve um alto grau de interação humana. E o exercício de técnica de cenários pode atender às necessidades de uma organização específica, não havendo possibilidade de aquisição de "pacotes" de cenários por mais de uma organização. Ou seja, cada organização deve definir a técnica mais apropriada e desenvolver, por meio da interação dos envolvidos, seus próprios cenários prospectivos.

Carvalho et al. (2011, p. 5) referem-se ao "método de cenários de Godet (2008)" dividindo-o em três grandes blocos:

a) Construção da base analítica e histórica: que é a representação do estado atual do sistema, incluindo a identificação das variáveis-chave e do conjunto de atores. Godet et al. (2008) recomendam que esta fase seja originada essencialmente em workshops que produzam um levantamento aprofundado e detalhado. Nesta etapa, as variáveis são definidas, classificadas e o relacionamento entre elas é analisado e estabelecido por meio de uma matriz. Tal matriz auxilia a classificar as variáveis segundo sua influência nos cenários e sua dependência de outras variáveis. Na análise da influência das variáveis, Godet et al. (2008) indicam que 
seja analisado não apenas seu relacionamento direto, mas que se analise também as relações indiretas e potenciais, que podem ser calculadas com o uso do software MICMAC, de autoria de Godet, desenvolvido em 1971, aplicado aos fatores chaves do desenvolvimento da energia nuclear, em 1974, conforme capítulo V, do manual de prospectiva estratégica (GODET, 2008). Quanto aos atores, são analisadas suas evoluções no horizonte dos cenários estudados, bem como os autores podem ser classificados como invariantes, tendências pesadas (afetarão variáveis por longo período) e fatos portadores de futuro (poucos perceptíveis no presente, mas que podem virar tendências pesadas e ficar relevantes no futuro). Por fim, é feita a análise da relação dos atores com as variáveis-chave.

b) Exploração do campo das possíveis evoluções: bloco que resulta do estudo das incertezas. De acordo com Ribeiro (1997), pelo método de Godet, é feita uma análise morfológica das variáveis e fatos portadores de futuro mais importantes e que, consequentemente, podem chegar a um grande número de potenciais cenários. É feita uma lista de combinações e possibilidades destes estados futuros, verificando restrições e incompatibilidades para combinar apenas conjuntos de estados futuros factíveis. A partir desta lista, uma matriz é construída com as combinações de maior contraste, para que passem por uma etapa de probabilização. Para a análise de probabilidade de cada combinação, Godet et al. (2008) também recomendam o uso de um software, o SMIC Prob-expert, que receberá o resultado da consulta a especialistas quanto às probabilidades de ocorrência de cada combinação em rodadas organizadas pelo software, que indicará o conjunto de combinações mais prováveis a partir das médias das notas dadas pelos especialistas.

c) Elaboração dos cenários: a partir dos conjuntos de combinações selecionados da etapa anterior, constrói-se o cenário de referência, com base na reunião dos conjuntos com maior probabilidade de ocorrência, além da construção de pelo menos um cenário contrastado, distinto do cenário de referência. De acordo com Godet et al. (2008), para cada cenário designado deve-se construir uma narrativa sequenciada, partindo da situação atual e chegando à visão de futuro determinada pelo cenário escolhido, destacando rupturas e mudanças que aparecerão em cada cenário, além da descrição de um caminho que possa conduzir da situação atual para a desejada.

Os autores acrescentam que o método de Godet possui estruturação rígida, baseada na análise dos itens de cenários e com o apoio de softwares, que realiza interações matemáticas. Com a redação dos cenários, Godet et al. (2008) recomendam mais três passos adicionais, relacionados à reflexão prévia, escolhas de planos estratégicos e elaboração / operacionalização / monitoramento de plano de ação. Estes passos adicionais executados trazem a garantia, segundo os autores, de se colocar em ação tudo o que foi elaborado nos passos anteriores.

\section{PROCEDIMENTOS METODOLÓGICOS}

Com base na abordagem teórica sobre metodologia científica e partindo da questão em estudo e do objetivo proposto, a pesquisa caracteriza-se como descritiva, dedutiva, tratase de abordagem quanti-qualitativa, considerando-se as interações entre o pesquisador e o mundo pesquisado. Neste caso, a comunidade contábil onde os fenômenos humanos 
acontecem, por criar e atribuir significados às inter-relações sociais e por usar o ferramental proposto por Godet (2008).

Para o desenvolvimento e análise dos cenários prospectivos, dentre as diversas abordagens, optou-se pela perspectiva de Godet (2008), em virtude de permitir analisar o objeto de estudo por meio de sua delimitação, de verificação das variáveis-chave, de identificar atores e objetivos e possibilitar traçar os possíveis cenários.

A primeira fase da construção de cenários requer uma base analítica e histórica com o objetivo de se obter uma imagem atual do sistema e do seu ambiente. Portanto, seguindo o método, foi feito um levantamento por meio de revisão de literatura no portal de periódicos e no banco de teses e dissertações da Coordenação de Aperfeiçoamento de Pessoal de Nível Superior (CAPES) sobre estudos e relatos de uso das comunidades de prática no período compreendido entre 2004 e 2016, delimitando o escopo do problema. Selecionaram-se os casos que apresentaram setores/organizações com CoP implantadas ou em implantação.

\subsection{Comunidades de prática consolidadas}

Conforme indicado pelo método escolhido para o desenvolvimento deste trabalho, o primeiro passo foi identificar fontes de informação que fornecessem subsídios para construção dos cenários. Para isso recorreu-se a uma revisão de literatura nacional por meio de busca no portal de periódicos da CAPES/CNPq sobre o estudo e implementação de comunidades de prática em diversas organizações. A escolha do portal CAPES/CNPq como fonte se deu pelos critérios de conveniência e acessibilidade. Verificaram-se nos casos analisados, algumas comunidades em estágio embrionário e outras já implantadas e em atividade. O Quadro 1 apresenta comunidades de prática encontradas na literatura no período de 2004 a 2016:

\begin{tabular}{|c|c|c|}
\hline \multicolumn{3}{|c|}{ Quadro 1 - Estudos de casos sobre comunidades de prática } \\
\hline AUTOR & ANO & ESTUDO/INSTITUIÇÃO DA CoP \\
\hline OLIVEIRA, H. M. et al. & 2016 & $\begin{array}{l}\text { Estudo realizado nas reuniões do Sindicato dos Contabilistas do } \\
\text { Estado de Goiás - SCESGO }\end{array}$ \\
\hline MORAES, M. G. & 2015 & $\begin{array}{l}\text { Comunidades de prática e representação da produção da rede } \\
\text { de laboratórios da UNIRIO }\end{array}$ \\
\hline ORSIOLLI, T. A. E. et al. & 2015 & $\begin{array}{l}\text { Comunidade de Práticas: uma Análise Multinível em um Grupo } \\
\text { de Pesquisa em Administração de uma IES Pública }\end{array}$ \\
\hline FERREIRA, T. B. & 2014 & $\begin{array}{l}\text { Desenvolvimento de competências laborais em ambiente de } \\
\text { aprendizagem social: estudo de caso com família de rendeiras } \\
\text { em Alcaçuz/RN }\end{array}$ \\
\hline PEDROSA, V. M. & 2014 & $\begin{array}{l}\text { Comunidades de Prática e Processos de Aprendizagem: um } \\
\text { Estudo com Coordenadores Técnicos de uma Escola Técnica - } \\
\text { Senai-PE }\end{array}$ \\
\hline GNECCO JR, L. et al. & 2012 & $\begin{array}{l}\text { A pesquisa foi desenvolvida nas quinze comunidades de prática } \\
\text { ativas da Associação Catarinense de Empresas de Tecnologia } \\
\text { (ACATE) }\end{array}$ \\
\hline MINOTTO, A. A. P. et al. & 2012 & $\begin{array}{l}\text { A Comunidade Virtual de Prática - CVP da Universidade Federal } \\
\text { de São Carlos (UFSCar) }\end{array}$ \\
\hline TAVARES, J. L. et al. & 2011 & $\begin{array}{l}\text { Um estudo de implantação de comunidades de prática em um } \\
\text { portal institucional. Propõe uma estrutura para dar suporte à } \\
\text { criação de CoP no Portal do Observatório OTICS }\end{array}$ \\
\hline CARVALHO, H. D. P. & 2010 & $\begin{array}{l}\text { Identificaram-se alguns pontos fortes e desafios na GRH do } \\
\text { IBGE/PE, apresenta recomendações a partir dos princípios } \\
\text { norteadores de redes e comunidades de prática }\end{array}$ \\
\hline FREITAS, D. P. S. & 2010 & $\begin{array}{l}\text { Comunidade de Práticas: Análise Multinível em um Grupo de } \\
\text { Pesquisa (MIRAR - Mediar, investigar, refletir, aprender, }\end{array}$ \\
\hline
\end{tabular}

Perspectivas em Gestão \& Conhecimento, João Pessoa, v. 7, n. 1, p. 170-190, jan./jun. 2017. 


\begin{tabular}{|l|c|l|}
\hline & 2010 & renovar) \\
\hline SILVA, A. M. N. H. & 2009 & $\begin{array}{l}\text { Comunidade de prática na biblioteca central do UNIPÊ } \\
\text { arranjos grupais. Estudo de caso sobre empresa de consultoria } \\
\text { organizacional V\&A- Valença \& Associados }\end{array}$ \\
\hline MOURA, G. L. & 2009 & $\begin{array}{l}\text { Resultados positivos de CoP reportados por empresas do setor } \\
\text { de Óleo \& Gás: Chevron Corporation e Schlumberger }\end{array}$ \\
\hline $\begin{array}{l}\text { CHUERI, L. O. V.; ROSA } \\
\text { NETO, J. M. }\end{array}$ & 2008 & $\begin{array}{l}\text { Arranjos Produtivos Locais (APL`s), analisaram a CoP criada pela } \\
\text { Rede Norte e Nordeste de Inclusão Social e Redução da Pobreza } \\
\text { (Rede NÓS) }\end{array}$ \\
\hline MARIA, A. S. R. I. et al. & 2007 & \begin{tabular}{l} 
Indústria de produtos químicos em São Paulo-SP \\
\hline $\begin{array}{l}\text { GROPP, B. M. C.; } \\
\text { TAVARES, M. G. P. }\end{array}$
\end{tabular}$\quad \begin{array}{l}\text { CoP da EMBRAPA. Após a reestruturação em 2003 a gestão das } \\
\text { Comunidades de Prática está a cargo da Superintendência de } \\
\text { Pesquisa e Desenvolvimento (SPD) }\end{array}$ \\
\hline VIEIRA, N. S. & 2005 & $\begin{array}{l}\text { Um Modelo para Fidelização em Comunidades de Prática, } \\
\text { baseado no Marketing de Relacionamento, para estimular a } \\
\text { participação em Comunidades de Prática }\end{array}$ \\
\hline GOUVÊA, M. T. A. & 2005 & $\begin{array}{l}\text { Comunidades de prática e articulação de saberes na relação } \\
\text { entre universidade e sociedade }\end{array}$ \\
\hline SCHOMMER, P. C. & $\begin{array}{l}\text { Criação de comunidades de prática virtuais. Projeto Piloto de GC } \\
\text { para o TJPE, utiliza a ferramenta Communis }\end{array}$ \\
\hline SILVA, E. H. V. S. C. & $\begin{array}{l}\text { Apresentação do caso Petrobras, KM Brasil } \\
\text { P\&D utilizam como ferramenta de apoio para os processos } \\
\text { finalísticos da empresa }\end{array}$ \\
\hline BATISTA, F. F. & 2004 \\
\hline
\end{tabular}

Fonte: Elaboração dos autores, 2016

Percebe-se que, nos casos estudados sobre comunidades de prática apresentados no quadro acima, possuem campo de estudo diversificado, apresentados em empresas de grande e pequeno porte, instituições públicas e privadas, bem como em setores de organizações, sindicato, universidade, demonstrando que a ferramenta de GC tem sido implementada nos diversos tipos de organização.

\subsection{Delimitação do problema e resultados esperados}

Diante da percepção da importância de se constituir uma contabilidade pública de estruturação eficiente e de eficácia duradoura, faz-se necessário estar preparado para as alterações que estão sendo implantadas com vistas a atendê-las até 2020.

A viabilidade de implantação de uma comunidade de prática para a área contábil, no sentido de proporcionar interação entre seus componentes, portanto, deve ser vista como cenário possível de interesse institucional.

Com o estudo de cenários prospectivos espera-se contribuir com a gestão administrativa no seu processo de tomada de decisão, com foco no desenvolvimento e implantação de uma comunidade de prática para o intercâmbio, o compartilhamento, a aprendizagem e a construção de conhecimentos, para alavancar o potencial da área, aperfeiçoar as técnicas, auxiliar o processo contábil e implementação da gestão do conhecimento.

\subsection{Recenseamento de variáveis e atores}

Perspectivas em Gestão \& Conhecimento, João Pessoa, v. 7, n. 1, p. 170-190, jan./jun. 2017. 
Para estabelecer as variáveis-chave que pudessem refletir a situação da área contábil e a possível implementação de uma comunidade de prática, foram realizadas consultas, por meio de questionário, a cinco técnicos do setor contábil da Universidade Federal da Paraíba UFPB, os quais trabalham na Coordenação de Contabilidade e Finanças (CCF), junto à PróReitoria Administrativa (PRA).

Propôs-se a elaboração de uma lista de variáveis internas e externas, bem como os possíveis atores internos e externos que pudessem influenciar na proposta da CoP. Posteriormente, foram definidas as variáveis internas que caracterizam o fenômeno estudado e as variáveis externas, que caracterizam o ambiente do fenômeno estudado, nos seus aspectos político, econômico, social, tecnológico etc. Identificadas as variáveis, o passo seguinte foi identificar os atores. Diante das respostas, as variáveis-chave foram assim definidas:

\subsubsection{Variáveis internas}

Foram consultados técnicos da área contábil sobre quais variáveis consideravam possíveis de afetar o grupo caso fosse implantado uma CoP.

Quadro 2 - Variáveis internas definidas pelos técnicos da CCF

\begin{tabular}{|l|l|}
\hline \multicolumn{1}{|c|}{ Variáveis } & \multicolumn{1}{c|}{ Descrição da variável } \\
\hline $\begin{array}{l}\text { Necessidade de } \\
\text { criação de uma CoP } \\
\text { na área contábil }\end{array}$ & $\begin{array}{l}\text { a CoP na área contábil torna-se necessária em virtude de se estar diante de } \\
\text { situação de mudanças das normas e procedimentos contábeis para o Setor } \\
\text { Público. }\end{array}$ \\
\hline $\begin{array}{l}\text { Competências dos } \\
\text { técnicos }\end{array}$ & $\begin{array}{l}\text { há no grupo, técnicos preparados e interessados em compartilhar seus } \\
\text { conhecimentos e abertos a receber contribuições de novas idéias. Bem como } \\
\text { apoiar e ministrar seminários e rodas de aprendizagem para demais membros do } \\
\text { grupo em caso de novidades e alterações de procedimentos. }\end{array}$ \\
\hline $\begin{array}{l}\text { Motivação para } \\
\text { participar da CoP }\end{array}$ & $\begin{array}{l}\text { a participação na CoP é voluntária, porém acredita-se que a maior motivação, } \\
\text { além do acréscimo de conhecimento, é poder contribuir para o crescimento da } \\
\text { área contábil, que se perfaz de tamanha importância no desenvolvimento e } \\
\text { atuação do profissional no Setor Público. }\end{array}$ \\
\hline $\begin{array}{l}\text { Cooperação entre os } \\
\text { membros da CoP }\end{array}$ & $\begin{array}{l}\text { os técnicos da área contábil têm como propósito demonstrar em seus relatórios } \\
\text { a situação orçamentária, financeira e patrimonial dos entes públicos aos quais } \\
\text { está vinculado e a colaboração mútua permite a padronização de procedimentos } \\
\text { na área, bem como o alcance e cumprimento das normas. }\end{array}$ \\
\hline
\end{tabular}

Fonte: Dados da pesquisa (2016)

\subsubsection{Variáveis externas}

Foram consultados técnicos da área contábil sobre quais variáveis externas consideravam possíveis de influenciar a implantação de uma CoP.

Quadro 3 - Variáveis externas definidas pelos técnicos da CCF

\begin{tabular}{|l|l|}
\hline \multicolumn{1}{|c|}{ Variáveis } & \multicolumn{1}{c|}{ Descrição da variável } \\
\hline $\begin{array}{l}\text { Alteração das normas } \\
\text { da organização }\end{array}$ & $\begin{array}{l}\text { as mudanças na tecnologia e nas normas de elaboração e apresentação das } \\
\text { demonstrações contábeis requerem mais envolvimento e discussão a respeito } \\
\text { dos procedimentos a serem adotados. }\end{array}$ \\
\hline Cultura na área & $\begin{array}{l}\text { a cultura arraigada no Setor Público da forma como é realizado o controle, o } \\
\text { qual passa por transformação e adequação a novas demandas estabelece nova } \\
\text { visão }\end{array}$ \\
\hline A legislação & o cumprimento da legislação e a limitação imposta pelos órgãos legisladores, \\
\hline
\end{tabular}

Perspectivas em Gestão \& Conhecimento, João Pessoa, v. 7, n. 1, p. 170-190, jan./jun. 2017. 


\begin{tabular}{|l|l|}
\hline & $\begin{array}{l}\text { de controle e do executivo, deve ser observada e cumprida pela área, bem } \\
\text { como sua aplicabilidade e eficácia no tempo. }\end{array}$ \\
\hline $\begin{array}{l}\text { Situação econômica } \\
\text { do país }\end{array}$ & $\begin{array}{l}\text { a crise porque passa o país e a necessidade de ajustes atinge todos os setores } \\
\text { da economia, incluindo a área contábil }\end{array}$ \\
\hline
\end{tabular}

Fonte: Dados da pesquisa (2016)

$\mathrm{Na}$ avaliação das respostas obtidas, foram definidos como atores internos, aqueles que podem influenciar na prospecção de CoP: Coordenador de Contabilidade e Finanças (CCF); os Diretores da Divisão de Contabilidade (DV); da Divisão de Administração Financeira (DAF); da Divisão de Acordos e Convênios (DAC); os chefes do Sistema de administração financeira (SIAFI); do Setor de Análise e Controle (SAC - Liquidação); contadores; e técnicos contábeis, além de colaboradores e gestor da Pró-reitoria administrativa (PRA).

Os atores externos foram definidos pelos técnicos consultados sobre quais órgãos/instituições influenciam na ferramenta proposta, obtendo-se como resposta: Conselho Federal e Regional de Contabilidade (CFC/CRC); Coordenadores de setores correlatos à Contabilidade; órgãos de controle; órgãos gestores.

\section{ANÁLISE DOS DADOS E ELABORAÇÃO DOS CENÁRIOS}

Depois de delimitado o escopo e definidas as variáveis-chave internas e externas e os atores internos e externos, parte-se para a análise dos cenários prospectivos com foco na implantação de comunidade de prática na área contábil do setor público educacional.

Com a utilização do aplicativo MICMAC do modelo de Godet (2011), que é alimentado por meio de uma matriz preenchida de acordo com a avaliação dos técnicos que foram consultados, os quais atribuem valoração de zero a três quanto a avaliação de interferência de uma variável em relação a outra, permite definir o grau de influência de cada variável estabelecida. Tem-se como resultado o seguinte mapa de influências/dependências diretas entre as variáveis-chave internas e externas, conforme Figura 1 que segue:

Figura 1 - Mapa de influências/dependências diretas

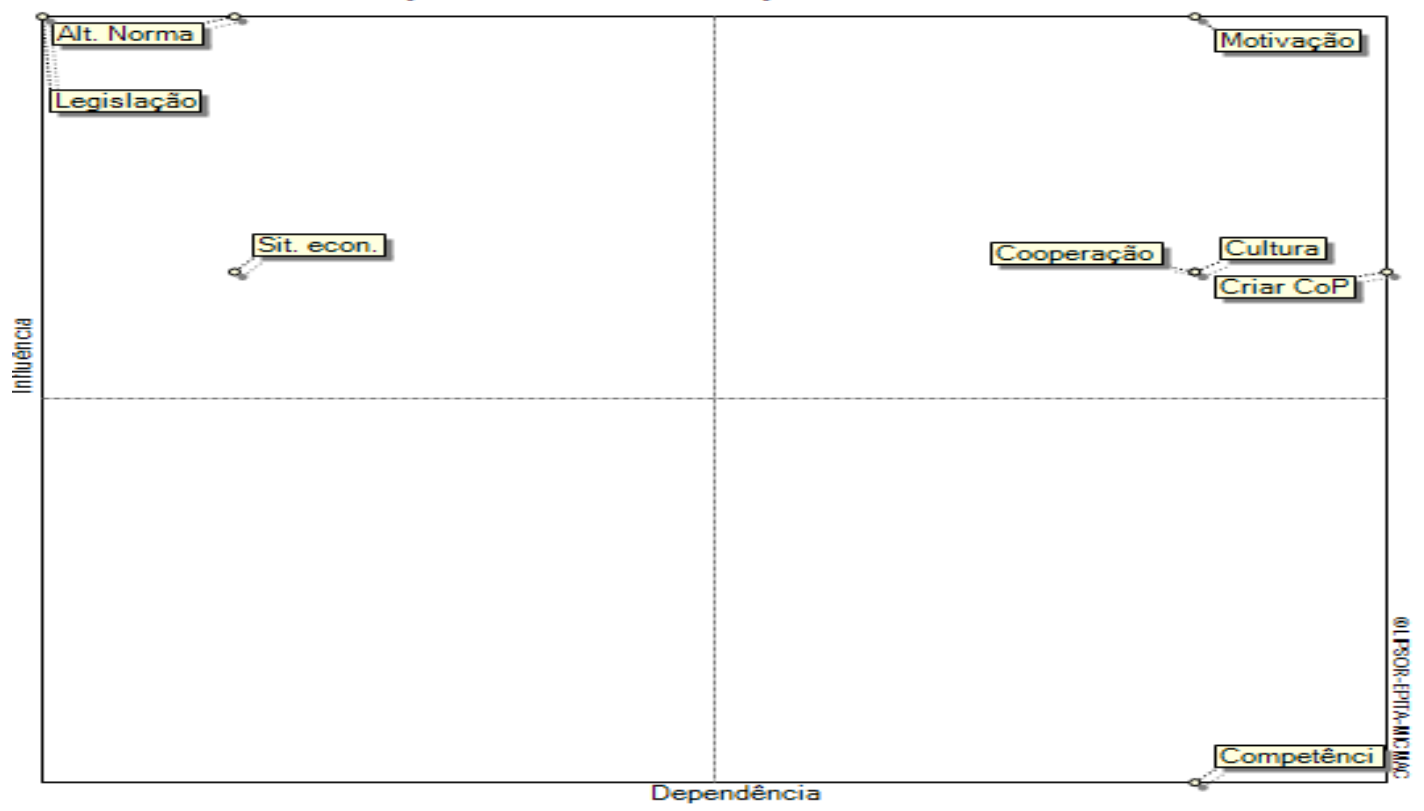

Fonte: Elaborado pelos autores, 2016 
Percebe-se que as variáveis de maior influência e pouca dependência, conforme o modelo estabelecido por Godet (2011) são: Alteração das normas; Cumprimento da legislação; e Situação econômica do país. As variáveis de maior influência e maior dependência são: Motivação dos técnicos para participar da CoP; seguidas pela Cultura na área; Cooperação entre os membros da CoP e Necessidade de criação de uma comunidade de prática na área contábil. Já a variável que tem pouca influência, mas com certa dependência é a Competência dos técnicos. Variável que está sobre influência indireta da legislação, conforme gráfico 2, 0 que faz sentido, uma vez que se trata de uma análise em unidades de gestão pública. Por sua vez autores como Silva (2010), Mengalli (2007) e Terra (2005) sugerem que a participação em comunidades de prática pode influenciar esta variável.

Pelo Gráfico 1 abaixo, identificam-se as influências diretas das variáveis-chave tanto internas quanto externas.

Gráfico 1 - Influências diretas

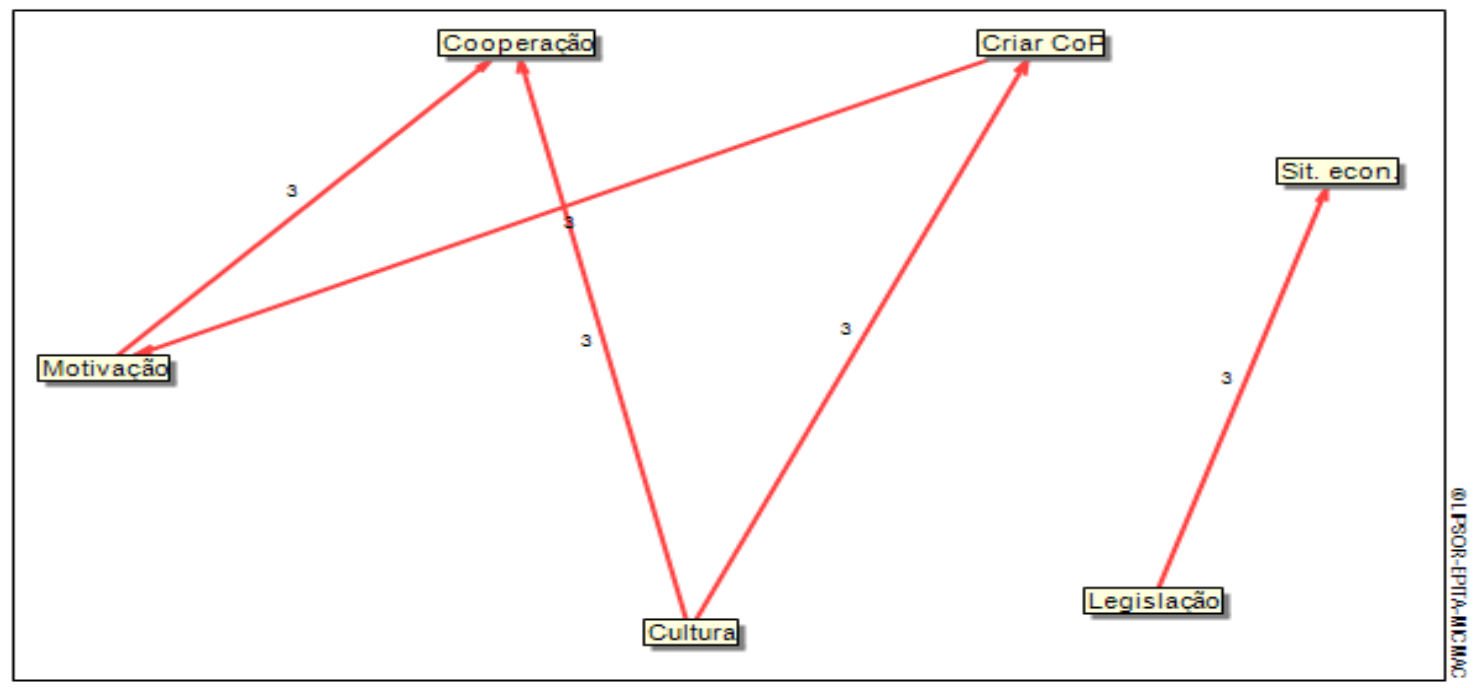

Fonte: Elaborado pelos autores, 2016

Pelo gráfico de influências diretas conforme modelo desenvolvido por Godet (2011) podem-se identificar as variáveis que mais tem influência entre si. Das variáveis externas apenas a Situação econômica do país e o Cumprimento da legislação apresentam esta relação.

Quanto ao gráfico de influências indiretas, desenvolvido com a aplicação do modelo de Godet (2011) constata-se que a variável Cumprimento da legislação influencia fortemente a Competência dos técnicos e a Motivação dos técnicos para participar da CoP. A Cultura na área influencia fortemente a Necessidade de criação de uma CoP na área contábil.

Já as variáveis Motivação dos técnicos para participar da CoP e Alteração das normas são influências mais importantes na Necessidade de criação de uma CoP na área contábil. Conforme pode ser visualizado no Gráfico 2: 
Gráfico 2 - Influências indiretas

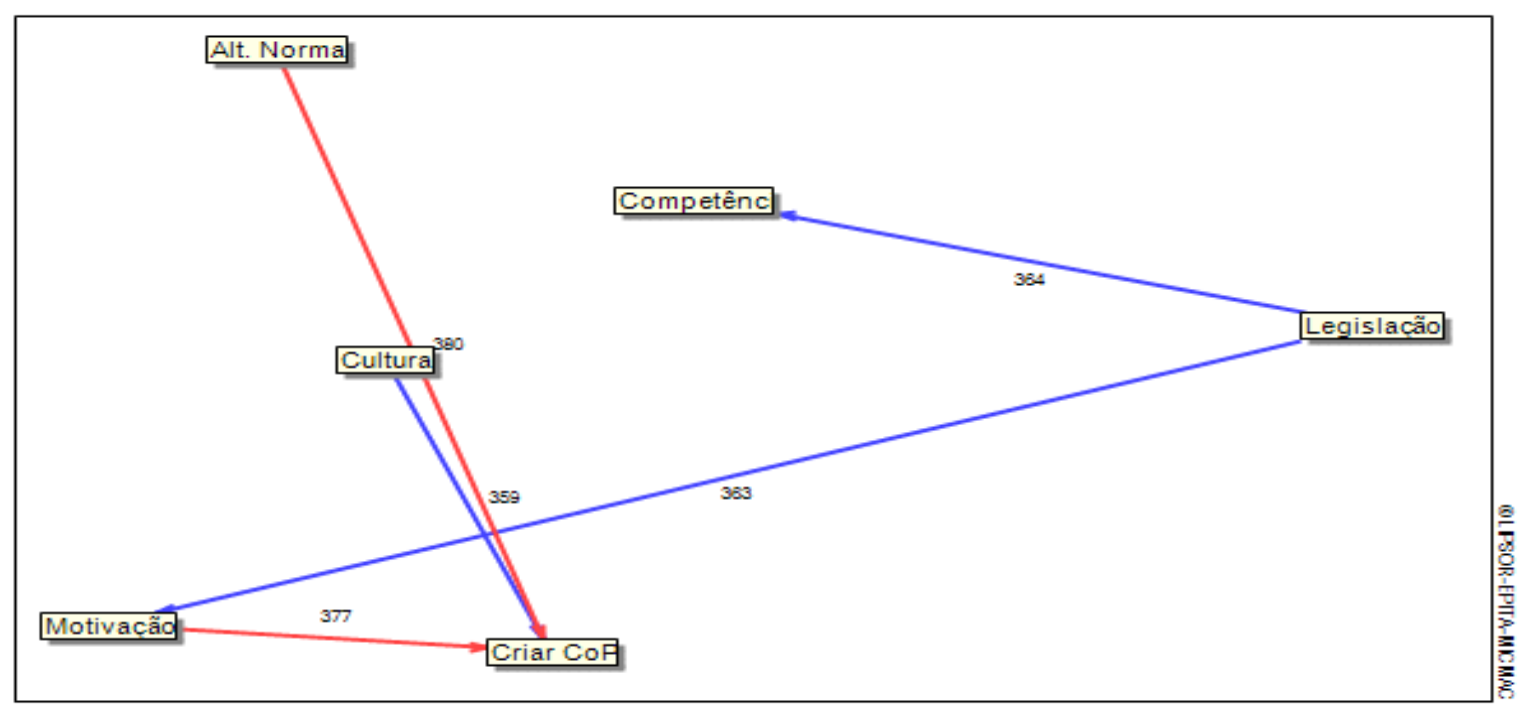

Fonte: Elaborado pelos autores, 2016

Esta relação entre variáveis foi percebida na pesquisa referenciada e desenvolvida por Lira (2012), por meio do diagnóstico de GC.

Com base no mapeamento representado nas Figuras 2 e 3 traçaram-se como objetivos relacionados aos cenários prospectivos: Incentivar a criação de uma comunidade de prática e estimular os técnicos a participarem (criar CoP); Executar programa de treinamento e uso da ferramenta comunidade de prática (cultura); Promover experiência de troca de informação e conhecimento na área (cooperação); Demonstrar a importância da comunidade de prática para o desenvolvimento da área contábil (motivação).

Figura 2 - Mapa de influências e dependências entre atores

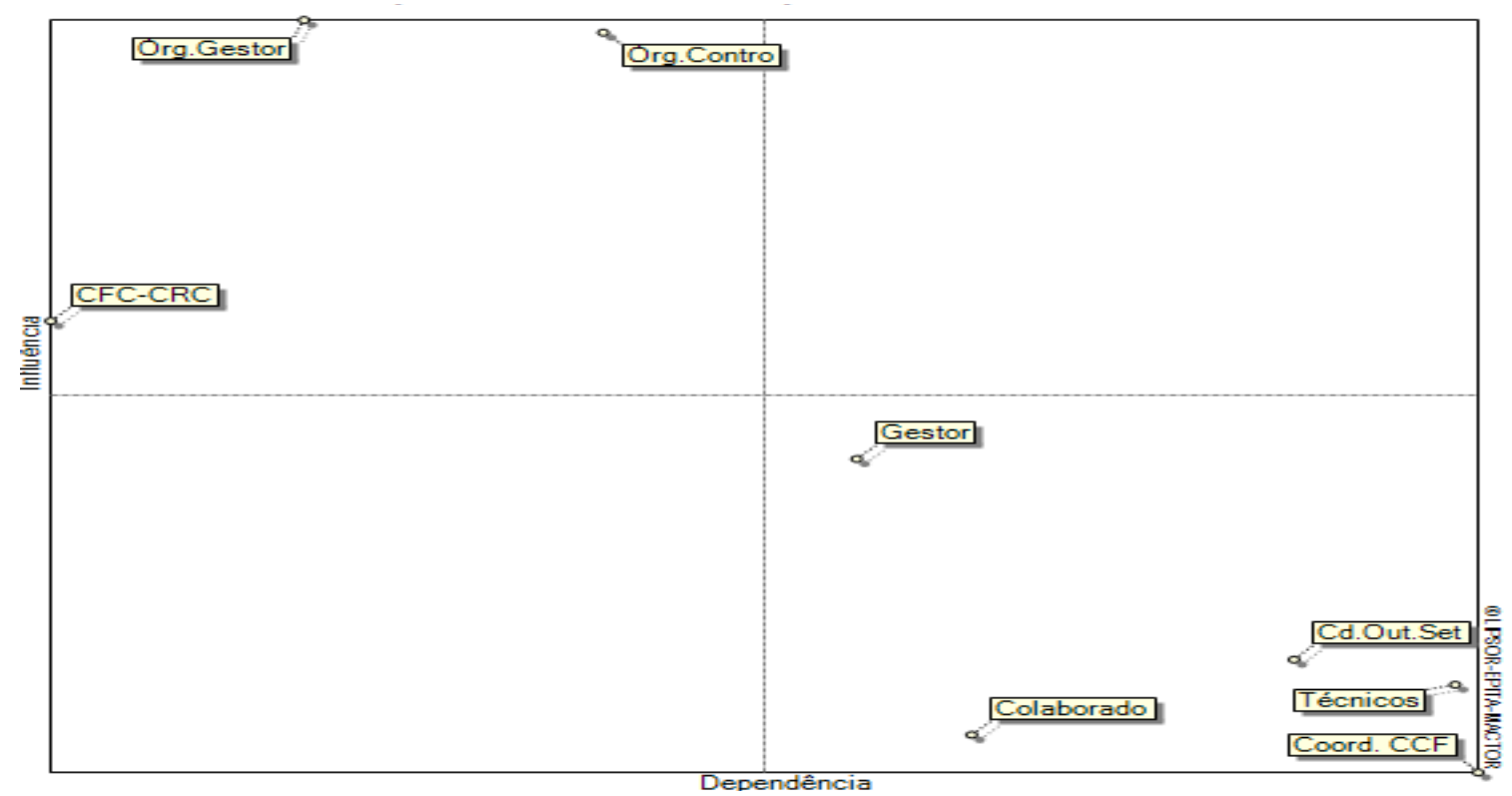

Fonte: Elaborado pelos autores, 2016

Perspectivas em Gestão \& Conhecimento, João Pessoa, v. 7, n. 1, p. 170-190, jan./jun. 2017. 
Com relação à análise da influência e dependência entre os atores, bem como da implicação dos atores sobre os objetivos traçados, utilizou-se o aplicativo MACTOR do modelo de Godet (2011), que parte de uma matriz de atores internos e externos, alimentado por meio de avaliação dos técnicos consultados, os quais atribuem o grau de influência de cada ator em relação aos outros e como resultado apresentam-se na Figura 2.

Verifica-se que os atores externos possuem maior influência, mas pouca dependência em sua maioria, apenas os Coordenadores de outros setores possuem maior dependência e pouca influência, assim como os atores internos que possuem pouca influência e maior dependência. Tal influência dos atores externos indica que as redes de compartilhamento podem ser uma opção para o desenvolvimento da CoP, propiciando redes mais estruturadas.

Oliveira e Cabral $(2015$, p. 355) reconhecem que,

Em termos práticos, as redes melhor estruturadas são aquelas nas quais se percebe maior flexibilidade para resolver problemas, sobretudo quando se trata da transposição de fronteiras, considerada como um fator cada vez mais importante devido ao surgimento de novas formas de conexão entre pessoas, em que organizações aparentemente isoladas passam a ocupar um espaço maior no mercado global. Nesse ponto, entende-se que a necessidade de compartilhar impulsiona o funcionamento das redes, tanto na natureza quanto na sociedade.

Na Figura 3, tem-se o mapa de convergências entre atores para avaliar quais atores tem maior grau de convergência entre si e os que convergem em menor grau.

Figura 3 - Mapa de convergências entre atores

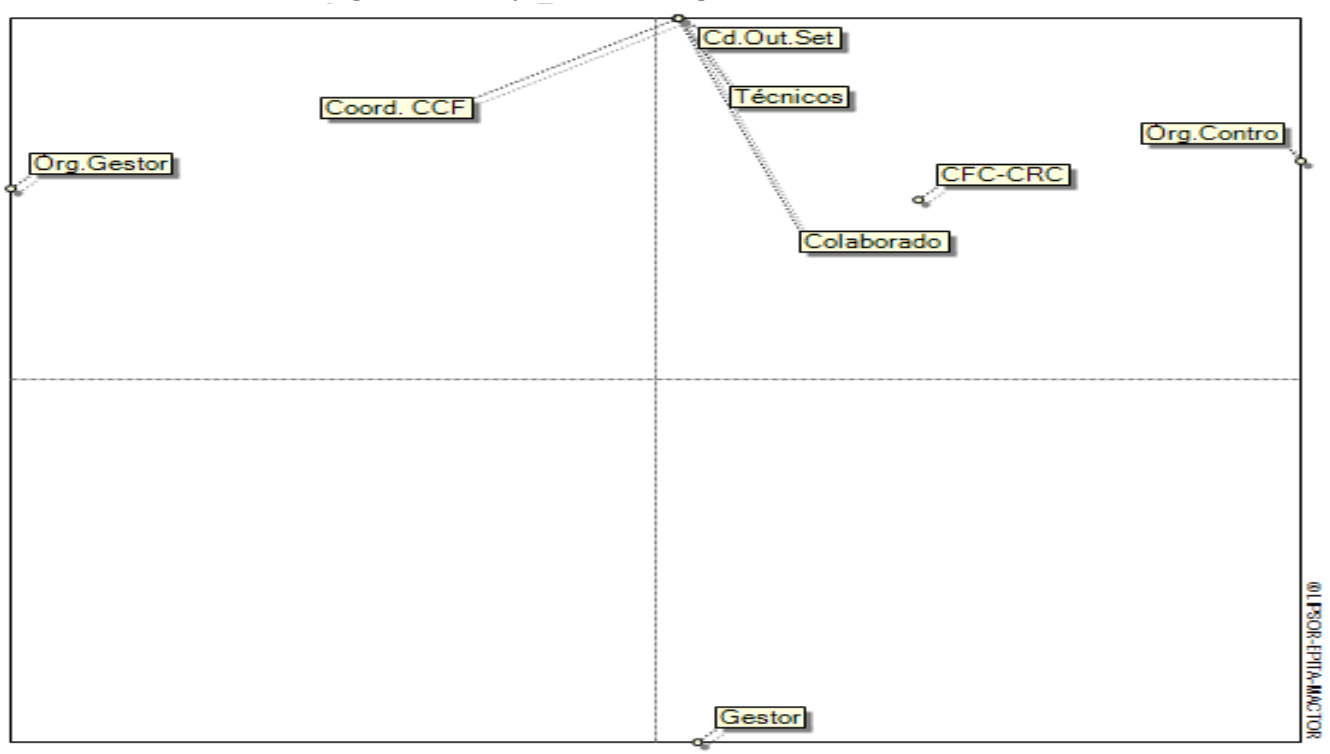

Fonte: Elaborado pelos autores, 2016

No mapa de convergência entre os atores, Figura 3, indica que os atores: Coordenador de contabilidade e finanças, Coordenadores de outros setores, técnicos e colaboradores têm convergência entre si.

Pode ser visualizado de forma melhor no Gráfico 3, onde se apresentam além das convergências mais fortes, as convergências mais fracas, como entre os atores: Órgãos de controle e Gestor.

Perspectivas em Gestão \& Conhecimento, João Pessoa, v. 7, n. 1, p. 170-190, jan./jun. 2017. 
Gráfico 3 - Convergências entre atores

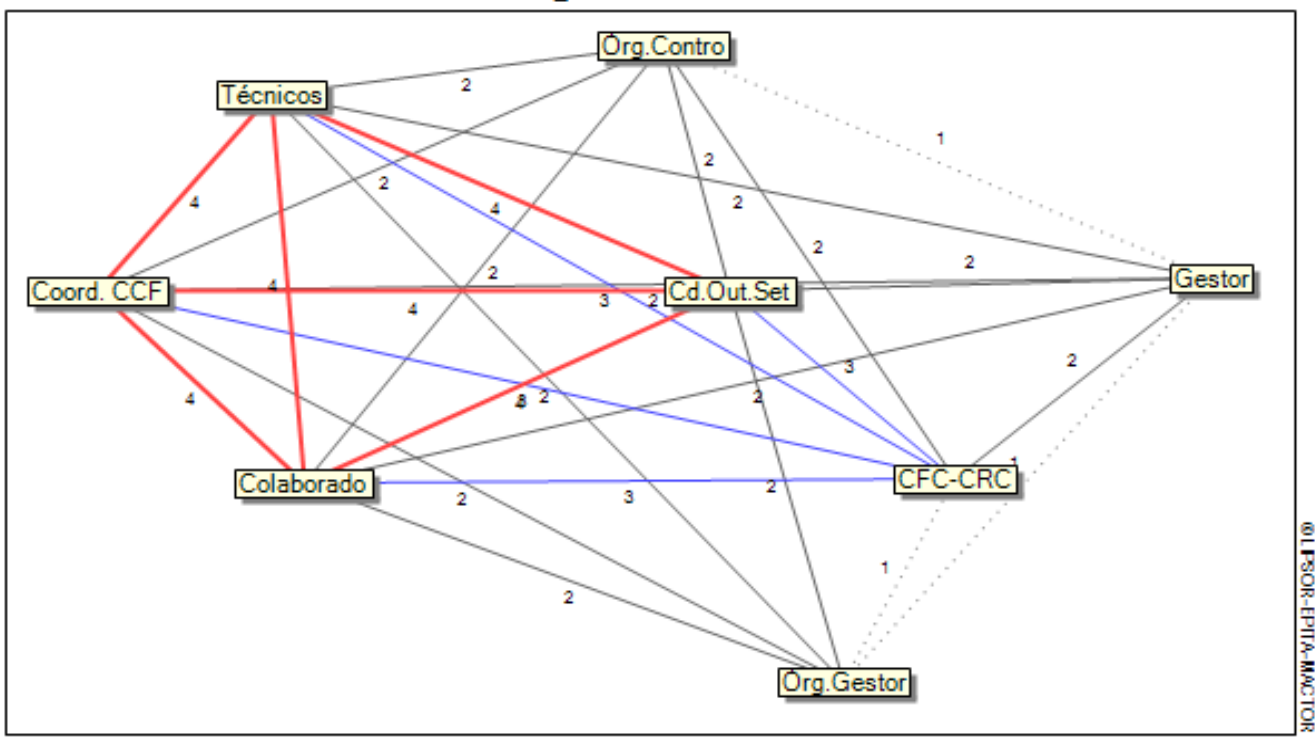

Convergências mais fracas

Convergências fracas

- Convergências moderadas

- Convergências fortes

- Convergências mais fortes

Fonte: Elaborado pelos autores, 2016

Para melhor visualizar a implicação dos atores sobre os objetivos, segue Figura 4:

Figura 4 - Histograma da implicação dos atores sobre os objetivos

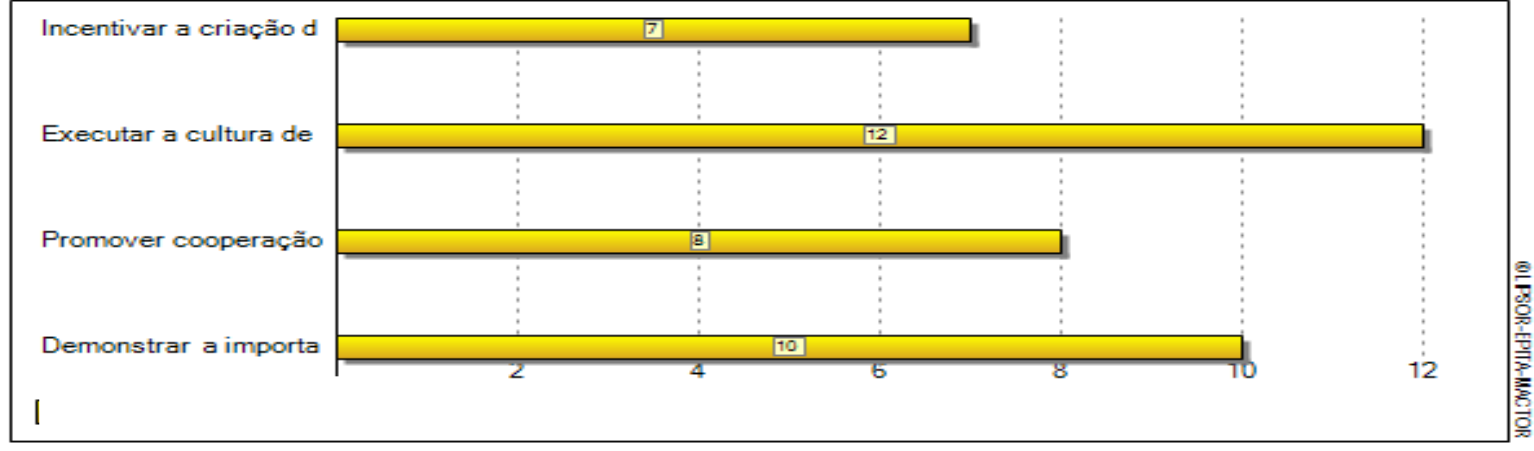

Fonte: Elaborado pelos autores, 2016

O histograma acima demonstra que dentre os objetivos traçados, o objetivo 2 (executar a cultura de compartilhamento como programa de treinamento e uso da ferramenta comunidade de prática) é o mais significativo para os atores, seguido pelo objetivo 4 (demonstrar por meio da motivação a importância da comunidade de prática para o desenvolvimento da área contábil).

O Gráfico 4 demonstra as distâncias líquidas entre objetivos e permite visualizar a relação dos atores com os objetivos, ou seja, situações de convergência (proximidade entre atores e objetivos) e divergência (distanciamento entre atores e objetivos). Este gráfico posiciona os objetivos em função da diferença entre a matriz das convergências e suas divergências de objetivos. 
Gráfico 4 - Distâncias líquidas entre objetivos

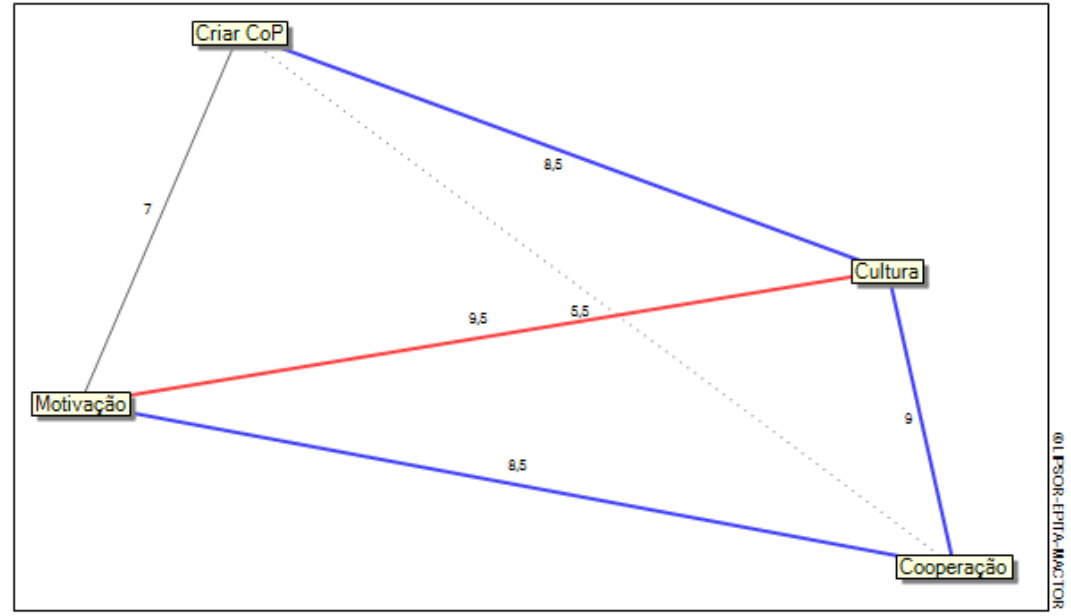

Distâncias liquidas mais fracas
- Distâncias liquidas fracas
- Distâncias liquidas moderadas
- Distâncias liquidas fortes
- Distâncias liquidas mais fortes

Fonte: Elaborado pelos autores, 2016

Os atores identificam distância líquida mais forte entre o objetivo 2 - Executar programa de treinamento e uso da ferramenta comunidade de prática (cultura) e o objetivo 4 Demonstrar a importância da comunidade de prática para o desenvolvimento da área contábil (motivação). E distância líquida fraca entre os objetivos: 4 - Demonstrar a importância da comunidade de prática para o desenvolvimento da área contábil (motivação) e 1 - Incentivar a criação de uma comunidade de prática e estimular os técnicos a participarem (criar CoP).

Para a análise morfológica, que avalia as variáveis e fatos portadores de futuro mais importantes para chegar a um número de potenciais cenários, foi feita uma lista de combinações e possibilidades destes estados futuros, verificando restrições e incompatibilidades para combinar apenas conjuntos de estados futuros factíveis, foram então, atribuídos grau de importância às variáveis internas e externas e grau de incerteza, os quais levaram a aplicação sobre as seguintes variáveis: a) Necessidade de criação de uma comunidade de prática na área contábil; b) Competências dos técnicos; c) Alteração das normas; d) Cultura na área. Os resultados apurados estão alinhados com o que foi descrito por Ribeiro (1997) e proposto por Godet et al. (2008).

\subsection{Cenários identificados}

Com base na análise das variáveis e atores, foram então construídos três cenários, conforme sugerido por Godet (2008): Bom para implantar CoP; Cautela para implantar CoP; Não implantar CoP.

1. Cenário "Bom para implantar CoP": neste, os participantes têm interesse na criação de uma CoP, há técnicos competentes que consideram importante o compartilhamento. Faz-se necessário uma alteração nas normas internas da organização para requerer urgência na implantação da CoP e existe uma cultura de mudança que se adéque as novas exigências.

2. Cenário "Cautela para implantar CoP": neste cenário, a criação de CoP é considerada importante e, os técnicos são maleáveis ao compartilhamento. Contudo, a alteração nas normas deve ser implantada paulatinamente e a cultura é transformada sem muita resistência. 
3. Cenário "Não implantar CoP": por fim com um foco menos otimista, os resultados indicam que a criação de CoP não é aceita pelos técnicos, que não têm interesse em compartilhar. A alteração nas normas não justifica a criação de CoP e a cultura organizacional permanece imutável.

\section{CONSIDERAÇÕES}

O presente artigo objetivou a análise de cenários prospectivos sobre a configuração e a possível implementação de uma comunidade de prática voltada para a área contábil, verificouse que o método selecionado ofereceu o suporte metodológico necessário para o trabalho proposto.

Para descrever os passos relativos à construção de cenários proposto por Godet (2008) dividiu-se em três seções: construção da base analítica e histórica, com o levantamento de exemplos bem-sucedidos de comunidades de prática encontradas na literatura, definiu-se a representação do estado atual de proposta de criação de uma comunidade de prática para a área contábil do setor público, incluindo a identificação das variáveis-chave e do conjunto de atores. As variáveis foram definidas, consultando-se os técnicos da área contábil da UFPB, em seguida foram classificadas e o relacionamento entre elas foi analisado e estabelecido por meio de uma matriz, em que foram analisadas suas relações diretas, indiretas e potenciais, calculadas com o uso do software MICMAC, de autoria de Godet. Quanto aos atores, também foram definidos por meio de consulta aos técnicos, analisadas suas evoluções no horizonte dos cenários estudados e feita análise da relação dos atores com as variáveis-chave e objetivos traçados.

Ressalta-se que conforme apresentado no tópico 3, que apresenta parte do referencial teórico abordado neste texto, o método de Godet não é o único que permite este tipo de desenvolvimento. Uma vez escolhido outro, é provável que o resultado seja diferente. Outro ponto que deve ser alertado é que, caso seja alterado o grupo consultado para o recenseamento dos atores internos e externos, os resultados também podem variar.

Posteriormente, foi realizada a exploração do campo das possíveis evoluções, com uma análise morfológica das variáveis e fatos portadores de futuro mais importantes. E por fim, partiu-se para a elaboração dos cenários a partir dos conjuntos de combinações selecionados.

Os cenários possíveis não são exaustivos, resume-se descritivamente as observações mais importantes quanto à prospecção de implementação de uma comunidade de prática na área contábil. O cenário "Bom para implantar CoP" estabelece que os participantes desta comunidade de prática devem possuir interesse desde sua criação, com participação ativa. Identificam profissionais com competências reconhecidas e dispostos ao compartilhamento. A alteração nas normas e procedimentos técnicos requer a implantação de CoP com certa urgência, para que haja troca de conhecimentos. A cultura organizacional se adéqua às novas exigências em caso de implantação de comunidade de prática na área contábil.

O cenário "Cautela para implantar CoP" reconhece que é importante a implantação de comunidade de prática; considera os técnicos maleáveis quanto ao compartilhamento de conhecimentos na área. A alteração nas normas deve ser aplicada e implantada ao longo do tempo. E a cultura organizacional não encontra muita resistência a mudanças.

Com relação ao cenário "Não implantar CoP" a criação e implementação de uma CoP não é bem aceita pelos técnicos, uma vez que estes não possuem interesse, nem motivação para compartilhar conhecimentos. A alteração nas normas e procedimentos não é considerada uma prerrogativa para criação de CoP, nem tampouco uma necessidade. E a cultura permanece imutável, ou seja, é muito resistente a mudanças.

Perspectivas em Gestão \& Conhecimento, João Pessoa, v. 7, n. 1, p. 170-190, jan./jun. 2017. 
Este trabalho não finaliza os estudos para implantação de uma CoP, contudo, fornece subsídios para tomada de decisão dos gestores envolvidos neste processo. O resultado é restrito pela visão dos participantes. A aplicação do mesmo método com um grupo maior ou com perfis diferentes pode apresentar outro tipo de resultado. Outro ponto que deve ser observado é o momento sócio/político em que o trabalho foi desenvolvido, pois este influencia tanto variáveis como atores externos de forma direta.

As análises realizadas e a descrição dos cenários identificados permitem o planejamento das etapas e podem auxiliar na elaboração de planejamento estratégico e tomada de decisão, atendendo ao objetivo proposto para o trabalho. 0 método de prospeç̧ão de cenários utilizado se mostrou adequado a proposta. Tais métodos podem ser aplicados nos estudos em Ciência da Informação, para auxiliar estudos sobre informação estratégica, gestão da informação e do conhecimento, prospeç̧ão de novas tecnologias, análise de mercado, entre outros.

\section{REFERÊNCIAS}

ÁLVARES, L. M. A. R. Telecentros de informação e negócios como veículo de educação corporativa nas microempresas e empresas de pequeno porte. 273f. Tese (Doutorado em Ciência da Informação) - Universidade de Brasília, Brasília, 2010.

ARAÚJO, C. A. Á. Fundamentos da Ciência da Informação: correntes teóricas e o conceito de informação. Perspectivas em Gestão \& Conhecimento, João Pessoa, v. 4, n. 1, p. 57-79, 2014. Disponível em: http://periodicos.ufpb.br/ojs/index.php/pgc/article/view/19120/10827.

BARBOSA, R. R. Gestão do conhecimento na literatura acadêmica: um estudo sobre a produção científica na base Scopus. In: ENCONTRO NACIONAL DE PESQUISA E PÓS-GRADUAÇÃO EM CIÊNCIA DA INFORMAÇÃO, 14., Brasília, 2013. Anais.... Brasília, 2013

CALAZANS, A. T. S. Conceitos e uso da informação organizacional e informação estratégica. Transinformação, Campinas, v. 18, n. 1, p. 63-70, jan./abr., 2006.

CÂNDIDO, C. A.; VALENTIM, M. L. P.; CONTANI, M. L. Gestão Estratégica da Informação: semiótica aplicada ao processo de tomada de decisão. DataGramaZero - Revista de Ciência da Informação, v. 6, n. 3, jun/ 2005.

CARVALHO, D. E. et al. CONSTRUÇÃO DE CENÁRIOS: apreciação de métodos mais utilizados na administração estratégica. In: ENCONTRO DA ASSOCIAÇÃO NACIONAL DE PÓS-GRADUAÇÃO E PESQUISA EM ADMINISTRAÇÃO, 35., Rio de Janeiro. Anais... Rio de Janeiro, 2011.

COHEN, M. F. Alguns aspectos do uso da informação na economia da informação. Ci. Inf., Brasília, v. 31. n.3, p. 26-36, set./dez. 2002.

DAVENPORT, T.; PRUSAK, L. Conhecimento empresarial: como as organizações gerenciam o seu capital intelectual. 15. Ed. Rio de Janeiro: Elsevier, 2003. 237p.

DUARTE, E. N.; LIRA, S. L.; LIRA, W. S. Gestão do conhecimento: origem, evolução, conceitos e ações. In: DUARTE, E. N.; LLARENA, R. A. S.; LIRA, S. L. (Org.). Da informação à auditoria de conhecimento: a base para a inteligência organizacional. João Pessoa. PB, Editora: UFPB, 2014. p. 269-308. 
DUARTE, E. N. et al. Aprendizagem informacional por meio do compartilhamento de conhecimentos entre docentes. In: ENCONTRO NACIONAL DE PESQUISA E PÓS-GRADUAÇÃO EM CIÊNCIA DA INFORMAÇÃO, 9., São Paulo. Anais.... São Paulo, USP, 2008.

DUARTE, E. N.; SILVA, A. K. A. Gestão da informação e do conhecimento: práticas de empresa excelente em gestão empresarial extensivas às unidades de informação. Inf. \& Soc.: Est., v. 17, n. 1, p. 97-107, jan./abr., 2007.

GODET, M. Da antecipação à ação: um manual de prospectiva estratégica. UNESCO Publishing. 2008.

GODET, M.; DURANCE, P. Prospectiva estratégica: para as empresas e os territórios. UNESCO. Ed. DUNOD. Versão portuguesa pela IEESF. Direção prof. Júlio G. Dias. 2011. 180p.

GODET, M.; DURANCE, P. Criando futuros: planejamento de cenários como ferramenta de gestão estratégica. Economica Ltd, França. 2006.

GRISI, C. C. H.; BRITTO, R. P. Técnica de Cenários e o Método Delphi: uma aplicação para o ambiente brasileiro. In: SEMINÁRIO EM ADMINISTRAÇÃO, 6., Rio de Janeiro. Anais... Rio de Janeiro, 2003.

GUTIERREZ, M. Perez-Montoro. Gestión del Conocimiento em las Organizaciones: Fundamentos, metodologia y praxis. Barcelona: Trea, 2008. 260p.

LEE, C.; SONG, B.; PARK, Y. Um instrumento para mapeamento de roteiro tecnológico baseado em cenários: Como avaliar os impactos de mudanças futuras nos planos organizacionais. Technological Forecasting \& Social Change, 90, p. 285-301, 2015.

LEITÃO, D. M. A informação como insumo estratégico. Ci. Inf., Brasília, v. 22, n. 2, p. 118-123, maio/ago. 1993.

MORESI, E. A. D.; PRADO, H. A.; ALCANTARA, A. Cenários prospectivos, monitoração ambiental e metadados. DataGramaZero - Revista de Ciência da Informação, v.11, n. 1 fev./2010.

MENGALLI, N. M. Conceitualização de comunidade de prática. Disponível em: http://www.projeto.org.br/emapbook/map neli.htm. Acesso em: 2 set. 2007.

OLIVEIRA, R. R.; CABRAL, S. M. Emergência de uma rede de conhecimento: análise segundo a experiência da criação e funcionamento do Centro Tecnológico do Agreste em Pernambuco. In: BASTOS, A. V. B.; LOIOLA, E.; REGIS, H. P. (Org.). Análise de redes sociais no contexto organizacional. Salvador: EDUFBA, 2015. p. 351-373.

PATEL, A. Gaining insight: Re-thinking at the edge. International Journal Technological Forecasting \& Social Change, n. 107, p. 141-153, 2016.

SILVA, A. M. N. H. Viabilidade de implementação de comunidades de prática (COP) para a gestão e compartilhamento da informação na Biblioteca Central do UNIPÊ. 141f. Dissertação (Mestrado em Ciência da Informação) - Universidade Federal da Paraíba, João Pessoa, 2010. 
SILVA, H. M. da; VALENTIM, M. L. P. Modelos de gestão do conhecimento aplicados a ambientes empresariais. In: VALENTIM, M. L. P. (Org.) Gestão da informação e do conhecimento no âmbito da Ciência da Informação. São Paulo: Polis: Cultura Acadêmica, 2008. p. $12-25$.

TAKIMOTO, T. Afinal, o que é uma comunidade de prática? Blog Sociedade Brasileira de Gestão do Conhecimento. Disponível em: http://www.sbgc.org.br/sbgc/blog/afinal-que-euma-comunidade-pratica. Publicado em 22 abril 2012. Acesso em 05 jun. 2015.

TARAPANOFF, K. Técnicas para tomada de decisão nos sistemas de informação. 2. ed. Brasilia: Thesaurus, 1995. $163 \mathrm{p}$.

TERRA, J. C. Comunidades de prática: conceitos, resultados e métodos de gestão. TerraForum, 2005.

WENGER, E. Communities of practice: learning, meaning, and identity. 1998. Disponível em: http://bit.ly/iJRaly. Acesso em: 14 jun. 2016.

Artigo recebido em 20/03/2017 e aceito para publicação em 21/06/2017 